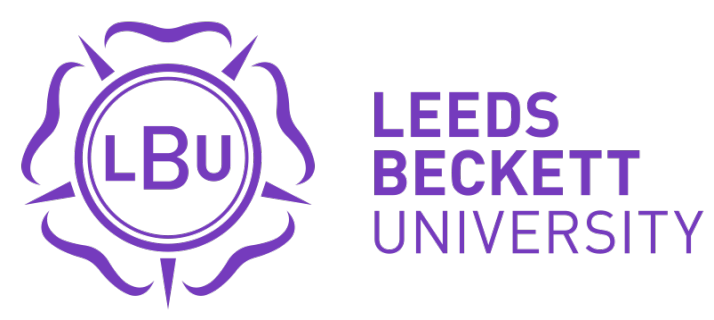

Citation:

Fletcher, TE and Hylton, K (2017) Race, ethnicity and whiteness in the governance of the events industry. Journal of Policy Research in Tourism, Leisure and Events, 10 (2). pp. 164-179. ISSN 1940-7963 DOI: https://doi.org/10.1080/19407963.2017.1406676

Link to Leeds Beckett Repository record:

https://eprints.leedsbeckett.ac.uk/id/eprint/4498/

Document Version:

Article (Accepted Version)

This is an Accepted Manuscript of an article published by Taylor \& Francis in Journal of Policy Research in Tourism, Leisure and Events on 27 November 2017, available online: http://www.tandfonline.com/10.1080/19407963.2017.1406676

The aim of the Leeds Beckett Repository is to provide open access to our research, as required by funder policies and permitted by publishers and copyright law.

The Leeds Beckett repository holds a wide range of publications, each of which has been checked for copyright and the relevant embargo period has been applied by the Research Services team.

We operate on a standard take-down policy. If you are the author or publisher of an output and you would like it removed from the repository, please contact us and we will investigate on a case-by-case basis.

Each thesis in the repository has been cleared where necessary by the author for third party copyright. If you would like a thesis to be removed from the repository or believe there is an issue with copyright, please contact us on openaccess@leedsbeckett.ac.uk and we will investigate on a case-by-case basis. 


\section{'Race', ethnicity and whiteness in the governance of the events industry}

Journal for Policy Research in Tourism, Leisure and Events

DOI: 10.1080/19407963.2017.1406676 (published online November 28, 2017)

Thomas Fletcher* and Kevin Hylton

School of Events, Tourism and Hospitality Management, Leeds Beckett University, UK

t.e.fletcher@leedsbeckett.ac.uk

Carnegie School of Sport, Leeds Beckett University, UK

In a recent policy debate in this journal, focusing on gender and the events industry, Rhodri Thomas states that his intention in writing the piece was to challenge policymakers and those working in representative organisations related to events to take equalities more seriously. The aim of this paper is to both react to this call and to make a similar one, explicitly challenging the need for more policy considerations and research into 'race', ethnicity and whiteness in the context of the events industry. While the notion of social justice is receiving greater scrutiny in the event literature, ideas of 'race', ethnicity and their intersections, and whiteness are neither currently addressed or understood. Many of the privileges afforded by whiteness processes rely on its reported invisibility, hegemony and supremacy. The first step in combating these privileges and their effects, is in explicitly identifying whiteness and making it visible. A simple acknowledgement that the lack of Black and minoritised ethnic people on the Boards of events organisations, is a good starting point, but alone, this is not enough. If the commitment to racial equality is to be more than a form of paying lip-service, then it is also necessary to engage with the deep-rooted cultural relations of power that sustain racially exclusive practices. If not addressed, the disproportionate number of leadership positions in events organisations will continue to perpetuate the 'snowy white peaks' of the industry's representative bodies.

Key words: Event, Governance, Organisation, Race, Social Justice, Whiteness

\section{Introduction}

In his recent policy debate in this journal, Thomas (2017) laments the 'remarkable absence of women' on the new Events Industry Board (EIB). He notes how the under-representation of women is stark given that most Events Management degree programmes in the United Kingdom (UK) are dominated numerically by women. Given the nature of his piece and the opportunities it presented to identify gaps in knowledge around equality and diversity in event organisations and the industry at large, we were surprised by the lack of attention paid to 'race' and ethnicity, more specifically to the whiteness of the events industry. Thomas does allude to intersectionality (p.202) and the existence of divergent 
forms of inequity in the workplace, but he stops short of naming the existence of whiteness and its antecedents. As we will discuss below, that whiteness is unnamed and is able to operate in plain sight, is partly why it is so entrenched and pernicious.

Thomas' piece takes as its starting point the formation of the EIB which, he states, 'comprises nine members, eight of which are men'. It is worth stressing here that each of those eight men is also White. The only exception to this rule on the Board is Ufi Abrahim, who is both a woman and Black and minoritised ethnic. ${ }^{1}$ The White maleness of the Board is impossible to deny, but is it representative of the events industry more broadly? If we delve deeper into the organisations that have representation on the EIB, the hegemony and normalisation of whiteness is apparent.

The Business Visits and Events Partnership (BVEP) comprises five Chairs/co-Chairs, of which three are White men and two White women. Its Secretariat consists of a further two White women. Scottish Event Campus' (SEC) Board of Directors has nine members, five of whom are White men and four are White women. Of London and Partners' 10 Board members, six are men, five of whom are White, and four White women. The Association of Event Organisers' (AEO) Chair is a White male and all of its 20 council members are also White men. There are 16 Board members of the Event and Visual Communication Association (EVCOM); 11 of whom are men, of which nine are White, and five White women. Finally, excluding Ufi Abrahim, who is Chief Executive of the British Hospitality Association, of the other 14 Board members, there are seven White women and seven White men. Taken collectively, of the 77 members sitting on the Boards of these leading organisations, only four - that is $3 \%$ - are Black and minoritised ethnic. Omi and Winant (2002) would point to racial processes that eventually lead to the 'snowy white peaks' that Kline (2014) observed in the United Kingdom's (UK) National Health Service (NHS). If not addressed, the processes that privilege White people and lead to them occupying a disproportionate number of leadership positions in events organisations will lead to the manifestation of 'snowy white peaks' of the industry's representative bodies.

It is instructive to consider why there is a blind spot on 'race' and ethnicity in regards to these new developments in the British events industry. Though this is a broad question, we could begin by focusing on the women in the sector. It reminds us of Mowatt et al's (2013) observation that even when we think about issues of equality we must consider the complex intersectional issues that Thomas alluded to in his article in this journal. For instance, when we consider gender and 'race', whose experiences and voices do we privilege? If the outcome of historical decision making has led us to privilege White, middle class, middle aged men then this call to neutralise the imbalance must be supported. Yet we must also be conscious of which women are privileged in any new interventions. For example, when we consider that women are under-represented in leadership and governance in events and require particular approaches to amend this disparity, one of the examples of interventions cited by Thomas, such as the mentoring programme by leading events company Fastforward15, itself lacks diversity (www.Fastforward15.co.uk). Fastforward15 has fifteen White mentors. This lack of reflexivity on the diversity of such interventions is the hallmark of well-meaning organisations that remain outward looking causing problems to remain 'out there' rather than starting 'in here'. In his paper in this journal Thomas described the intervention as, 'dynamic and enlightened leadership that will, no doubt, help retain talent and serve the sector well' (p.203). If the intervention is to be successful it needs to consider its starting point for whom it seeks to retain and serve. The 
representation and imagery of mentors, whose role it is to encourage diversity, and the mentor and mentee testimonials, force us to pose the question which women are being encouraged?

Further, the Association of British Professional Conference Organisers (ABPCO) board that Thomas joined is a successful example of women executives in the sector. Three out of fifteen of the executive are men which is quite a role reversal for most sectors. However, as many professionals have an ambivalence to images of whiteness the 14 White men and women remain unremarkable and would only seem so if, in an alternate reality, there was a marked majority of Black and minoritised ethnic Board members. It is when we see such bodies out of place, that do not fit a somatic norm, that we begin to recognise that 'race' is significantly absent from policy and academic debates in the events industry. The invisibility of whiteness in this message is revealed in the heralding of diversity without 'race' having a place. A context that for unrepresented others reinforces their marginality in the sector while perpetuating what some would argue is a hierarchy of oppression at structural and sectoral levels. Thomas (2017: 204) concludes his policy debate paper by stating:

My intention is to challenge policy-makers and those working in representative organisations related to events to take equalities more (conspicuously) seriously. Their role as leaders affords them the opportunity that others lack to ensure that the sector genuinely embraces the diversity of talent available. I also hope that this short commentary will encourage researchers to undertake work which will assist policymakers.

The aim of this paper is to both react to this call and to make a similar one, explicitly challenging the need for more policy considerations and research into 'race', ethnicity and whiteness in the context of the events industry. We must be prepared to work through some of the uncomfortable realities of debating how we think about diversity and under-representation especially in regard to patriarchal and racialised systems of inclusion and exclusion. We adopt the view that White identity is not just phenotypic, but is also dynamic, performative and contingent. We are also mindful that whiteness processes, while not always acknowledged, are omnipresent; permeating all facets of everyday life, including the workplace and leisure spaces. Indeed, whiteness operates at a number of levels of the workplace - from recruitment to governance structures. The recent reviews into 'race' in the workplace (McGregor-Smith, 2017) and UK National Health Service (NHS) (Kline et al. 2017) are cases in point.

\section{Situating 'race', ethnicity and whiteness in the context of events}

While the notion of social justice is receiving greater scrutiny, for example, in the context of event hosting (see Dowse and Fletcher, 2017; Finkel, 2015) and gender (see other contributions in this issue), ideas of 'race', ethnicity and their intersections, and whiteness are neither currently addressed nor understood in the events literature. This absence can be partly explained by the relative infancy of events management education and research, coupled with the tendency of events management literature to prioritise operational considerations over issues of equality and diversity. The absence of research into issues, which seem so fundamental to us as social scientists, reflects a number of criticisms facing 'mainstream' events management literature, as put forward by Jago (2012), Rojek $(2012,2013)$ and Dashper, Fletcher and McCullough (2017) amongst others, which argue that event- 
related research needs to become more critical and theoretically rigorous. For instance, Rojek (2013: 18), while clearly aiming to provoke, argues:

in focusing on the operational, technical aspects of event design, publicity and management, event professionals unwittingly obscure the relationship of events to deeper, wider questions of history, power, personal gratification, control and resistance.

Such calls to account for intersecting structures of power, control and resistance have been consistent features in our own work. We are united by our commitment to anti-racism and social justice, and in our beliefs that the multifarious ideological underpinnings of whiteness lie at the heart of this fight. It is important to stress here that a focus on social justice must be coupled with the belief in the existence of 'injustice', before change can occur. As we identify below, many of the privileges afforded by whiteness processes rely on its reported invisibility, hegemony and supremacy. The first step in combating these privileges and their effects, is in explicitly identifying whiteness and making it visible. A simple acknowledgement that the lack of Black and minoritised ethnic people on the Boards of events organisations, as identified at the outset, is a good starting point.

Studies of whiteness arguably lag behind other areas of ethnic and racial studies. As Frankenberg (1993) previously noted, meaningful conversations with White people about 'race' are muted due to their denial of seeing 'race' and/or the polite distancing of the topic. Early studies of whiteness asserted that White people do not see themselves as 'raced', yet enjoy privileges as a result of their whiteness (McIntosh, 1988). These ideas have been supplemented by the defence of White privilege through colourblindness (Leonardo, 2009; Bonilla-Silva, 2010), learned ignorance (Mills 1997, Sullivan and Tuana 2007), meritocracies and broader ideals of level playing fields (Gillborn, 2008) and notions of racism's demise emerging in post-race discourses (Hylton and Long, 2015; Gilroy 1998, St. Louis 2002). The result of conscious or unconscious ambivalence toward White privilege leads to a legacy of what has been described as 'White supremacy', where systematic insidious processes of privileging manifest themselves across a plethora of arenas as racial outcomes (Omi and Winant 2002) and include, but are not restricted to, housing, education, health, economics, media, or leisure (including events) (Gillborn, 2008).

Historically, whiteness has been viewed as normal, with many academics alluding to the invisibility of White ethnicities (Dyer, 1999; Garner, 2007). Of course, this view is demonstrative of academic White logic because White ethnicities are always visible to Black and minoritised others in the way that W.E.B. Du Bois' emphasised ideas of the veil, and double consciousness (Fanon, 1986[1967]; Du Bois, 1998). Classic writers in racial and ethnic studies such as Du Bois and Fanon began to articulate such ideas, later applied in critical race theory, that began with the call for racialised subjectivities to inform the disruption of racialised social arrangements (hooks, 1992; Crenshaw, 1995). So convincing is the 'White as invisible' thesis that Nayak (2003) refers to White ethnicities as 'cultureless', while Bonnett (2005) has termed White, the 'Other of ethnicity'. Leonardo (2009) suggests that whiteness gains a significant amount of its power by 'Othering' the very idea of ethnicity. These views beg the question of how whiteness acts implicitly through routine and normalised practices within social environments as a consequence of a White-centred culture.

If we are to derail the multifarious workings of whiteness, it is necessary to ask a number of questions of whiteness and the different ethnic groups encumbered by it: 1 ) Where and with whom should the 
awareness and responsibility for whiteness lie? 2) How responsible and aware of whiteness should those with White identities be? 3) How should Black and minoritised ethnic groups relate to whiteness? 4) How might White people become conscious and critical of the privileges of whiteness to the betterment of Black and minoritised ethnic groups? (adapted from Roberts, 2009: 497). At the core of these questions is the supposition that 'rather than simply describing what whiteness is, it is more useful to explain what whiteness does' (McDonald, 2009: 9) and how its harmful effects can be derailed and its power used with social justice at the centre.

In recognising this, a more complex view has emerged which recognises that racism and more recent turns to forms of 'bias' (overt/covert, direct/indirect, intentional/unintentional) is not simply down to the actions of a minority of disturbed individuals, rather that it can exist within entire institutions and organisations (Fletcher and Hylton, 2016). According to Lord Herman Ouseley, former Chair of the anti-racism charity, Kick it Out, as a result of affirmative action taken following the establishment of campaigns like Kick it Out, there has been an effective shift within (sport) policy discourses towards recognising that:

the outcomes resulting from decisions made by those in power who, in spite of commitments to equal opportunities and fair treatment, uphold traditions, cultures and policies and practices which are insufficiently radical or robust to eliminate or mitigate the adverse effects of race, sex and class discrimination. (Ouseley, 2011: ix)

As research into 'race' and event policy becomes more well-established, perhaps we will see similar calls for positive action in the context of event organisations. Such developments involve a paradigm shift about the nature of inequalities and disparities, and an imperative for change that moves policymakers from regulative to redistributive approaches.

\section{'Race', ethnicity and whiteness in the context of organisational culture}

The Board of any organisation is the key decision-making entity of that organisation. It is important therefore, that the Board is equipped to represent the individuals and communities who belong or may later be attracted to the organisation and its activities (Zanoni et al., 2010). A diverse and talented Board and workforce is widely accepted as a business necessity in the contemporary global marketplace, and is underpinned by two broad arguments. The first is a social justice case: everyone has the right to be treated fairly in the workplace, regardless of sex, 'race', disability status, sexuality, age, or any other characteristic (Long, Fletcher and Watson, 2017). The second argument is commonly referred to as 'the business case'. Diverse organisations perform better on a range of measures (Grimes, 2001). Organisations need to capitalise on diversity for five reasons: 1. Taking advantage of diversity in the labour market; 2. Maximising employee potential; 3. Managing across borders and cultures; 4 . Creating opportunities and enhancing creativity; and 5. Appealing to a wider participation base.

Increasing diversity at Board and senior management level is acknowledged as a priority by business, governments and regulators, as well many shareholders and customers. Research suggests that more organisational diversity is associated with improved financial performance, good corporate governance and facilitates better decision making by bringing different perspectives to challenging 
dialogues (Miller et al., 2009; King et al., 2011; McGregor-Smith, 2017). According to the Equality and Human Rights Commission (2016), companies with a diverse leadership operate more effectively and innovatively by understanding their customers, being more open to change and recruiting the best talent (Kline, 2014). As highlighted throughout this paper, event organisations have tended not to reflect the diversity of the communities in which they are embedded, being dominated by White, middle class, middle aged, able-bodied men.

There is a paucity of research on 'race', ethnicity and whiteness in the context of events (see Griffin, 2012; Hylton and Morpeth, 2012; Winter, 2013; Davidson, 2014 as exceptions) and no research in the context of event organisational culture. Consequently, a transdisciplinary approach is necessary to look to evidence found elsewhere. There is a well-developed body of literature which has focused on organisational diversity (Oswick and Noon, 2014), some of which emphasises 'race' and ethnicity (Van Laer and Janssens, 2011; Noon, 2017). There is however, a lack of work that explicitly addresses whiteness and organisational culture (see Grimes, 2001; Reitman, 2006). Of that which does exist, we find the work of Gabriel and Tate (2017) Inside the Ivory Tower and Nirmal Puwar's (2004) classic Space Invaders instructive. Both present an intersectional interrogation of space, including case studies of Black and minoritised ethnic women working in higher education (Gabriel and Tate) and Westminster and Whitehall (Puwar). Puwar's analysis takes as its starting point the view that diversity and representation are not the same as inclusion and moreover, that diversity and representation in one role does not, de facto, lead to diversity and representation in other aspects of an organisation. For example, at our own institution (like most UK Higher Education institutions), Black and minoritised ethnic people are mainly located at lower grades, but heavily under-represented in senior management roles. A pay gap between White and Black and minoritised ethnic staff also exists. According to the Times Higher Education Pay Survey (Baker, 2017), for professional and support roles, the overall average pay gap between Black and White staff in 2015-16 was 7.3 per cent - rising to 12.6 per cent for senior administrative posts. Among academics, Black staff were paid 12.6 per cent less than their White colleagues, while for Asian academics, the gap was 10.4 per cent. Most striking however, there are just 95 Black staff at professorial level out of a total of more than 20,000 (Kline, 2017).

It is worth noting that employment statistics alone remain limited as they are unable to provide contextual insights into the experiences of those within the workplace. Indeed, in the context of sports, Hylton and Chakrabarty (2011) argue that positive news stories about on-field representation can often mask social exclusions and problematic recruitment policies, rendering cultures of inequity invisible. We cannot assume that improved representation of Black and minoritised ethnic people in event organisations would signal either the end of racism or indeed, of White privilege. In his review of 'race' and ethnicity in the NHS, Kline (2014) uncovered a series of machinations which contribute to 'race' discrimination. These included: differential success at interview of White and Black and minoritised ethnic candidates; disproportionate access to career development; disproportionate disciplinary action against Black and minoritised ethnic staff; and disproportionate bullying of Black and minoritised ethnic staff. In an earlier review of leadership interventions in the health service aimed at Black and minoritised ethnic staff, Esmail et al. (2007) identified the following organisational barriers as typical reasons why there is a lack of senior level diversity: racially biased recruitment and selection practices; undervaluing of relevant experience and overseas qualifications; tokenism; rewards (some evidence suggested that the allocation of excellence awards is discriminatory against 
Black and minoritised ethnic groups and women); cultures of whiteness; lack of Black and minoritised ethnic mentors/role models; exclusion from informal networks; stereotyping, which led to preconceptions over abilities and role allocation. Gabriel and Tate (2017) go on to explain the complexities of organisational culture that reveal blind spots where intersections of 'race' and gender are poorly understood, thus privileging some women over racialised others. They would concur with Puwar who argued, it is one thing to occupy a space, it is quite another to have an "undisputed right to occupy the space" (Puwar, 2004: 1).

Many of the workings of whiteness, therefore, are subtle and their effects individually experienced. Schmalz and Mowatt (2014) refer to the existence of subtle forms of social and environmental prejudice, which they believe are demonstrated in the attitude that 'marginalised groups already have all the rights they need', and that 'prejudice and discrimination is not an issue in today's society'. On this basis, they argue how '[I]ndividuals who are prejudiced in subtle ways might claim to be "colorblind"; that demands made by marginalized groups are unfair to other groups; or that efforts to accommodate for or account for discrepancies in opportunities are undue' (p.247). They identify four ways subtle forms of prejudice are manifest. Firstly, ambivalent prejudice, which refers to mixed emotions about a group that stem from contradicting values. The supposition here is that while a White person may, in principle, support egalitarian and meritocratic ideas, for example, that Black and minoritised ethnic people might benefit professionally from targeted interventions, the same person would be less supportive of an intervention if it was seen to negatively affect them personally. A good example here would be the introduction of a system designed to improve the representation of Black and minoritised ethnic people. The second form, Aversive prejudice, like ambivalent prejudice is founded on egalitarian notions of society. The proposition is that inequality is maintained through one group's aversion and avoidance of another, which becomes justified. For instance, as we argue here and as others argue in this special issue (e.g. Dashper), minority groups, whether minoritised on the basis of 'race', gender or something else are denied roles and progression, not because of their 'race' or gender, but on the basis of their 'ability' to perform the necessary tasks. The third form, Benevolent prejudice refers to the association of apparently positive emotions or attitudes towards a group, but manifests in keeping members of that group in lower or inferior positions to one's own. A good example would be mentoring and how some mentors may intentionally sabotage the opportunities of their mentees. It might manifest in limiting Black and minoritised ethnic individuals to lower level careers, receiving lower pay for doing the same jobs, and providing fewer opportunities to both access and progression within certain roles. Finally, Symbolic prejudice, subscribes to the notion that stereotypes exist because they are rooted in truth, and thus oppose policies and interventions to promote equality. Here, majority groups, in this case White people, explain the existence of inequality on the basis that it is justified. For example, economic disparities between White and Black ethnic groups are due to Black people's lack of motivation to work hard (see Sears and Henry, 2005).

Mirroring the subtle forms of prejudice identified by Schmalz and Mowatt (2014), Puwar (2004) argues that whiteness too works in subtle ways that profoundly affect Black and minoritised ethnic people; the most conspicuous being in their attempts to fit into White spaces. She refers to the process of 'whitewashing' and argues that adherence to the norms and values of the hegemonic culture facilitates, not only entry, but progression too. Reitman (2006), in her examination of White work spaces argues similarly that whitewashing simultaneously denies race and superimposes White culture. The whitewashed workplace, she argues, like a whitewashed wall, is seen as colourless. Within 
these contexts, Puwar (2004) warns that Black and minoritised ethnic people cannot change their visible skin colour difference, but instead choose to 'perform' their identities in a way that positions them closer to the dominant and valued identities of particular White spaces. As she explains:

Whilst they have to accept that skin colour is a permanent feature of their bodily appearance, they can change or slowly 'whitewash' bodily gestures, social interests, value systems and speech patterns ... Adherence to the norms and values of this hegemonic culture is almost a condition of entry.

Such a view is reminiscent of Fanon's (1986[1967]) conceptualisation of the 'white mask'. Fanon conceived that for Black and minoritised ethnic people to succeed in areas of life dominated by White people they have to adapt their image, behaviour, language and culture to better reflect those of the White majority; effectively de-racialising their identity. Thus, the removal of difference is on the terms of the dominant culture and moreover, acceptance into the dominant culture is conditional on Black and minoritised ethnic individuals de-prioritising their own cultural history and identities. Goldberg (1996: 185) articulates this process further:

Black people are faced with the dilemma that the principal mode of progress and selfevaluation open to them is precisely through self-denial, through the effacement, obliteration, of their blackness. They are predicated, that is, upon the possibility of rendering a significant feature of their self-definition invisible, if not altogether effaced.

In addition to a number of highly personal and highly embodied challenges facing Black and minoritised ethnic people in White dominated spaces, we must also account for how Black and minoritised ethnic people are perceived by the White majority. According to Puwar (2004), as racialised bodies are seen as visible carriers of their ethnicities, unlike White bodies, they are perceived to be marked and bounded by their ethnic identities. Thus, they are forced to carry a 'burden of representation' in that, $s /$ he is 'seen to represent the capacities of groups for which [s/he] is marked and visible' (Puwar, 2004: 58). Similarly, in this role, Black and minoritised ethnic people are simultaneously subjected to the White 'gaze' (hooks, 1992); inscribing their position as objects of fascination which, it has been argued, leaves them open to excessive scrutiny and criticism. Goldberg (1996) for instance, observes how in whiter spaces, Black and minoritised ethnic people are placed under 'super-surveillance'. As a result, the tiniest error in performance or judgement can be highlighted and amplified as proof of the person not being quite up to the job.

What some of the published literature lacks, though not all, is a critical examination of not only the experiences of those who are marginalised, but also and more precisely, a call to action for what should be done to bring about social justice, change, and the (re)distribution of power among more diverse groups of people.

\section{Do event organisations need an anti-racism framework?}

In the policy context then it is necessary for event organisations to work together and with others to help them achieve a sophisticated understanding of the dynamics of 'race' (and racism) in order to facilitate the development of policies for planning, promoting, overseeing and evaluating racial 
(in)equality. To facilitate our discussion and as a point of comparison, we draw upon Sporting Equals' Race Equality Charter for sport.

The evidence from a survey by Sporting Equals in 1999 to gauge the approach of governing bodies to racial equality indicated a general resistance to discuss these issues. Of 62 national governing bodies surveyed, half did not respond, while 50 per cent of those that did claimed that racial discrimination was not a problem in their sport (Sporting Equals, 2000). Such results exemplify our earlier point that where individuals do not see themselves as raced they have the privilege of being able to ignore it without being affected by such decisions. A culture of colour blindness can operate in organisations with little diversity through policies, custom and practice that do not necessarily require the conscious bias of individuals. In producing the Racial Equality Charter for Sport, Sporting Equals appear to recognise that patterns of racial inequality in terms of participation, management and support are intimately related to a culture of racism that permeates British sporting establishments. Details in the Charter reveal that racial inequality is not seen as being divorced from racial discrimination and, in a novel departure for policy makers, representation in aspects of sport apart from participation is recognised (Carrington et al. 2016).

The first signatories to the Charter included the Chief Executives of Rugby Football League, Rugby Football Union, UK Athletics, England and Wales Cricket Board, English Basketball, Amateur Swimming Association and the National Coaching Foundation (Sporting Equals, 2000). The Charter required organisations to acknowledge that they have an active role to play in establishing mechanisms to combat racial inequalities before they are embedded in everyday practices and, where they are already evident, organisations are responsible for identifying racism(s) and addressing their cause. It encouraged governing bodies and organisations to provide evidence that they were working towards race equality objectives by developing Race Equality Action Plans and by monitoring the people taking part in the sport by age, gender, disability and ethnic origin. It also provided a means to measure the outcomes of its policies and action plans. Sporting Equals devised a four-tier 'quality mark' Standard - Foundation, Preliminary, Intermediate and Advanced - which indicated the level of achievement by the organisation. Crucially, according to Spracklen and Long (2011: 69) evidence of achievement against the objectives of the Standard was later linked by Sport England to continued funding of governing bodies, which meant that every governing body funded by Sport England (excluding one) would achieve the Preliminary level by early 2003 (though there was no indication of when organisations would be expected to achieve the Intermediate and Advanced levels).

The Standard was at least partially successful in 'pushing' sports organisations to develop policies on racial discrimination, though was certainly not without its critics. In their evaluation of the Standard's impact Long et al. (2003) suggested that impact was only partial, and commitment to racial equality did not in practice permeate down the structures of organisations. They concluded that although there is now a greater recognition of the importance of racial equality, such policies are not given a high priority within sports organisations, are actively resisted by those who are reluctant to acknowledge the presence of racial inequality and thus often lose out when faced with competing demands for more 'important' projects. The authors also noted that racial equality policies are often championed by individuals or very small groups within organisations - known as the 'equality people' - and are particularly vulnerable to staff changes as a result. Spracklen and Long (2011) also note that 
engagement with the Standard was meant to be seen as a developmental process for sporting organisations, but that some viewed their achievement of the Preliminary level as a satisfactory end point. Ahmed (2006) described such behaviours as 'speech acts' that ultimately represented symbolic behaviours that enabled 'non-performance' in regards to race equality. Just the act of 'working towards' race equality was used as evidence of success. Events organisations must be wary of such partial approaches to diversity in the sector. Moreover, Spracklen and Long (2011) questioned the rigour of how the Standard was monitored; that is organisations tended to engage with the Standard in very calculated ways; embedding the objectives of its Preliminary level in their policies and plans - doing enough to secure funding - but not necessarily in their practices. ${ }^{2}$ Following this, Shaw (2007) has argued that by conceptualising a social justice aim such as equality as measurable and tangible, the Standard ignored 'the complex power and political relations that are inherent in considering the intersectionality of marginalised and under-represented groups' (cited in Rankin-Wright et al. 2016: 358).

As an attempt to establish a regulative framework the Sporting Equals Standard is an example of how change can be slow, how good intentions can be circumvented, and how necessary it is for those at the highest levels to adopt and ensure a sustainable mainstream approach to implementation. A later study by Sporting Equals on governance and ethnicity in national governing bodies demonstrates the resilience of organisational cultures to resist diversity change (Sporting Equals 2016). In a survey of 68 national governing bodies Sporting Equals' Leaderboard identified 1 Black and minoritised ethnic CEO, 1 Chair, and only 26 out of 601 Board members. However one views the success of their earlier work there seems to be little legacy of this effort in regards to leadership and governance over a decade and a half later. In working seriously towards bettering their practices towards diversity and meritocracy, it is crucial, as Thomas (2017: 201) suggests, that event organisations, at the very least, 'recognise the existence of bias and to reflect upon the analysis of those who challenge the status quo.'

\section{Conclusion}

Existing research (e.g., Carrington et al., 2016; Fletcher and Hylton, 2016; Rankin-Wright et al., 2016) has identified that the failure of policy makers and organisations in prioritising racial equality and diversity can be partially attributed to the lack of understanding over its workings, and a subsequent reluctance to acknowledge and talk about it. This is further exacerbated when we consider how specific under-represented groups struggle where women are the focus of interventions. An intersectional approach is one that would help to focus where efforts need to be marshalled so that equalities interventions move beyond the 'lowest hanging fruit'. Rather than burying one's head in the sand however, Gillborn (2008) argues that racial equality should be 'placed centre-stage as a fundamental axis of oppression' (p.1).

Managing diversity is not simply about recruiting more diverse individuals into organisations, proactive measures need to be taken to support individuals, facilitate better communication, and embed fair and transparent practices that are open to everyone. Neither is diversity just a numbers game, and quotas alone are not effective in changing organisational cultures and practices to be more inclusive. Integral to the success of embedding diversity at the highest levels of (event) organisations 
is a wholesale change in organisational culture to become one where difference and diversity are celebrated, alternative viewpoints welcomed, and recruitment, training and reward practices open, transparent and equitable (Kline, 2014; Kline et al., 2017). Perhaps more importantly, decision makers within organisations must be held accountable for their approaches to improving and managing diversity. This is because, as Sara Ahmed (2007) notes in the context of Higher Education institutions, there exists a new politics of documentation, which takes diversity and equality as measures of institutional/organisational performance. Writing documents that express a commitment to promoting race equality is now a central part of equality work. However, rather than assuming such documents do what they say, Ahmed suggests we need to follow such documents around, examining how they get taken up, applied and evaluated. She warns that, when taken up as tokenistic gestures, such documents work to conceal dysfunctional institutional cultures that reify subtle forms of racism.

There is growing recognition among policy makers and practitioners that a progressive policy framework for eradicating racial bias and inequalities represents the start of the process rather than being an end in itself (Ahmed 2006). In the current social climate, overt forms of prejudice and obscene forms of discrimination are no longer tolerable. Institutions are careful, through their representatives, to 'ignore or circumvent weak [anti-discrimination] law, but rather construct compliance in a way that, at least in part, fits their interests' (Edelman, 1992, cited in Schmalz and Mowatt, 2014: 249). Carrington et al (2016) argue that if racism(s) is to be eradicated from different organisations and institutions those involved in the process need to have a nuanced understanding of the racism(s) to be contested. Their argument is based on the assumption that much 'anti-racism is essentially reactive' because 'it is defined by the racism it opposes' (Long and Spracklen, 2011: 7). In other words, if the commitment to racial equality is to be more than a form of paying lip-service, then it is also necessary to engage with the deep-rooted cultural relations of power that sustain racially exclusive practices. Without such a shift, then the danger is that the campaign for racial equality may become little more than a managerial response by bureaucratic organisations compelled by law to show they have policies on equity in place, but understanding little and doing less about the entrenched cultures of racial exclusion.

In the context of the event industry, we are at the very beginning with these debates. As a starting point we need to know more and we need to start a conversation. There needs to be more research into the experiences of access and progress within event organisations for both Black and minoritised ethnic people and their White counterparts. There also needs to be more research into the culture of event organisations. By raising awareness and collective consciousness of whiteness and White privilege, those already working and those aspiring to work in the events industry will be better equipped to recognise racialised inequalities and, more importantly, once these are recognised, they can subsequently disrupt and challenge them.

\section{References}

Ahmed, S. (2007) The language of diversity. Ethnic and Racial Studies, 30(2): 235-256.

Ahmed, S. (2006) The nonperformativity of antiracism. Meridians: feminism, race, transnationalism, $7(1):$ 104-126. 
Baker, S. (2017) Times Higher Education Pay Survey 2017 [online] available from https://www.timeshighereducation.com/features/times-higher-education-pay-survey-2017

[accessed 31 October, 2017].

Bonilla-Silva E. (2010) Racism without racists: Color-blind racism and the persistence of racial inequality in the United States Lanham, Maryland: Rowman \& Littlefield Pub Inc.

Bonnett, A. (2005) Anti-racism. London: Routledge.

Carrington, B., Fletcher, T. and McDonald, I. (2016) The politics of 'race' and sports policy in the United Kingdom. In Houlihan, B (ed.) Sport in society $3^{\text {rd }}$ edition. London: Sage.

Crenshaw K. (1995) Critical race theory : the key writings that formed the movement. New York: New Press.

Dashper, K., Fletcher, T. \& McCullough, N. (2017) Sport events, society and culture. London: Routledge.

Davidson, J. (2014) Racism against the abnormal? The twentieth century Gay Games, bipower and the emergence of homonational sport. Leisure Studies, 33(4): 357-378.

Dowse, D. and Fletcher, T. (2017) Sports mega-events, the non-West and the ethics of event hosting. Sport in Society, published online ahead of print, DOI: 10.1080/17430437.2018.1401359.

Du Bois WEB. (1998) Black Reconstruction in America 1860-1880. New York: The Free Press.

Dyer, R. (1997) White: Essays on 'Race' and Culture. London: Routledge.

Esmail, E., Kalra, V. \& Abel, P. (2007) A critical review of leadership interventions aimed at people from black and minority ethnic groups [online] available from http://www.aneezesmail.co.uk/PDF\%20files/HealthFoundReport.pdf [accessed 27 October, 2017].

Fanon, F. (1986[1967]) Black skin, white masks. London: Pluto.

Finkel, R. (2015) Introduction to special issue on social justice and events-related policy. Journal of Policy Research in Tourism, Leisure and Events, 7(3): 217-219.

Fletcher, T. (2011) "Aye, but it were wasted on thee": 'Yorkshireness', cricket, ethnic identities, and the 'magical recovery of community'. Sociological Research Online, 16(4), available from http://www.socresonline.org.uk/16/4/5.html

Fletcher, T. (2012) "All Yorkshiremen are from Yorkshire, but some are more 'Yorkshire' than Others": British Asians and the myths of Yorkshire cricket. Sport in Society, 15(2): 227-245.

Fletcher, T. and Dowse, S. (forthcoming 2017) Sports mega-events, the non-West and the ethics of event hosting. To be published in Sport in Society.

Frankenburg, R. (1993) White Women, Race Matters: The social construction of whiteness. London: Routledge.

Gabriel, D. and Tate, S. (Eds) (2017) Inside the Ivory Tower: Narratives of women of colour surviving and thriving in British academia. London: Trentham.

Garner, S. (2007) Whiteness: an introduction. London: Routledge. 
Gillborn D. (2008) Racism and Education: coincidence or conspiracy? London: Routledge.

Gilroy, P. (1998) Race ends here. Ethnic and Racial Studies, 21(5): 838-847.

Goldberg, D.T. (1996) In/visibility and super/vision. In Gordon, L., Sharpley-Whiting, T. \& White, R (eds) Fanon: A critical reader. Oxford: Blackwell.

Griffin, R.A. (2012) The disgrace of commodification and shameful convenience: A critical race critique of the NBA. Journal of Black Studies, 43(2): 161-185.

Grimes, D. (2001) Putting our own house in order: whiteness, change and organization studies. Journal of Organizational Change Management, 14(2): 132-149.

hooks b. (1992) Representing whiteness in the Black imagination. In Grossberg, L (ed.) Cultural studies. London: Routledge: pp.338-346.

Hylton, K. and Chakrabarty, N. (2011) "Race" and culture in tourism, leisure and events. Journal of Policy Research into Tourism Leisure and Events, 3(2): 105-108.

Hylton, K. and Morpeth, N.D. (2012) London 2012: 'race' matters and the East End, International Journal of Sport Policy and Politics, 4(3): 379-396.

Hylton, K. and Long, J. (2015) Confronting 'race' and policy: 'how can you research something you say does not exist?' Journal of Policy Research in Tourism, Leisure and Events, 8(2): 202-208.

Jago, L. (2012) Endnote. In Shipway, R. \& Fyall, A (eds) International sports events. London: Routledge, 221-223.

King, E.B., Dawson, J.F., West, M.A., Gilrane, V.L., Peddie, C.I. \& Bastin, L. (2011) Why organizational and community diversity matter: Representativeness and the emergence of incivility and organizational performance. Academy of Management Journal, 54: 1103-1118.

Kline, R. (2014) The "snowy white peaks" of the NHS: a survey of discrimination in governance and leadership and the potential impact on patient care in London and England. London, Middlesex University.

Kline, R. (2017) Sustaining change in workplace race equality: What works and what doesn't. Keynote address for Leeds Beckett University's Race, Equality and Diversity Forum annual Race Lecture. Leeds Beckett University: Leeds, October 18.

Kline, R., Naqvi, H., Razaq, S.A. \& Wilhelm, R. (2017) NHS workforce race equality standard, available from https://www.england.nhs.uk/wp-content/uploads/2017/03/workforce-race-equality-standarddata-report-2016.pdf (accessed 12 June, 2017).

Leonardo Z. (2009) Race, whiteness, and education. New York ; London: Routledge.

Long, J., Fletcher, T. \& Watson, R. (2017) Introducing sport, leisure and social justice. In J. Long., T. Fletcher and R. Watson (eds) Sport, leisure and social justice. London: Routledge, pp.1-14.

Long, J., Robinson, P. and Welch, M. (2003) Raising the standard: an evaluation of progress. Leeds: Coachwise. 
Long, J. and Spracklen, K. (2011) Positioning anti-racism in sport and sport in anti-racism. In Long, J. \& Spracklen, K (eds) Sport and challenges to racism. Basingstoke: Palgrave Macmillan.

McDonald, M.G. (2009) Dialogues on whiteness, leisure and (anti)racism. Journal of Leisure Research, $41(1): 5-21$.

McGregor-Smith, R. (2017) Race in the workplace: The McGregor-Smith review, available from https://www.gov.uk/government/uploads/system/uploads/attachment data/file/594336/race-inworkplace-mcgregor-smith-review.pdf (accessed 12 June, 2017).

McIntosh P. (1988) White privilege and male privilege: A personal account of coming to see correspondences through work in women's studies. Wellesley, MA: Wellesley College Centre for Research on Women.

Miller, R. \& Del Carmen Triana, M . (2009) Demographic Diversity in the Boardroom: Mediators of the Board Diversity-Firm Performance Relationship Journal of Management Studies Volume 46, Issue 5, pages 755-786, July 2009).

Mills C. (1997) The Racial Contract. Ithaca: Cornell University.

Mowatt, R.A., French, B.H. and Malebranche, D.A. (2013) Black/female/body hypervisibility and invisibility: A Black feminist augmentation of feminist leisure research. Journal of Leisure Research, 45(5): 644-660.

Nayak A. (2003) 'Ivory Lives': Economic Restructuring and the Making of Whiteness in a Postindustrial Youth Community. European Journal of Cultural Studies, 6(3): 305-325.

Noon, M. (2017) Pointless diversity training: Unconscious bias, new racism and agency. Work, Employment and Society, published online ahead of print. DOI: 10.1177/0950017017719841.

Omi, M. and Winant, H. (2002) Racial formation. In Essed, P. and Goldberg, D.T (eds) Race critical theories. Oxford: Blackwell.

Oswick, C. \& Noon, M (2014) Discourses of diversity, equality and inclusion: Trenchant formulations or transient fashions? British Journal of Management, 25(1): 23-39.

Ouseley, H. (2011) Foreword: Challenging racism in and through sport: Masculinity, power and supremacy. In Long, J. \& Spracklen, K (eds) Sport and challenges to racism. Basingstoke: Palgrave Macmillan.

Puwar, N. (2004) Space invaders. Oxford: berg.

Reitman, M. (2006) Uncovering the white place: whitewashing at work. Social \& Cultural Geography, 7(2): 267-282.

Roberts, N.S. (2009) Crossing the color line with a different perspective on Whiteness and (anti)racism: A response to Mary McDonald. Journal of Leisure Research, 41(4): 495-509.

Rojek, C. (2012) Global Event Management: a critique. Leisure Studies, 33(1): 32-47.

Rojek, C. (2013) Event power: How global events manipulate and manage. London: Sage. 
Schmalz, D.L. and Mowatt, R.A. (2014) The Unsettling Nature of Prejudice. Journal of Leisure Research, 46(3): 245-251.

Sears, D.O. and Henry, P.J. (2005) Over thirty years later: A contemporary look at symbolic racism. Advances in Experimental Social Psychology, 37: 95-150.

Sporting Equals. (2000) Achieving racial equality: a standard for sport. London: Sport England/CRE.

Sporting Equals. (2016) Who's on board in sport? Birmingham: Sporting Equals.

Spracklen, K and Long, J. (2011) Using charters and standards to promote anti-racism in sport. In Long, J. \& Spracklen, K (eds) Sport and challenges to racism. Basingstoke: Palgrave Macmillan.

St. Louis, B. (2002) Post-race/post-politics? Activist-intellectualism and the reification of race. Ethnic and Racial Studies, 25(4): 652-675.

Sullivan S and Tuana N. (2007) Race and epistemologies of Ignorance. Albany: State University of New York Press.

Thomas, R. (2017) A remarkable absence of women: a comment on the formation of the new Events Industry Board. Journal of Policy Research in Tourism, Leisure and Events, 9(2): 201-204.

Van Laer, K. \& Janssens, M. (2011) Ethnic minority professionals' experiences with subtle discrimination in the workplace. Human Relations, 64(9): 1203-1227.

Winter, A. (2013) Race, multiculturalism and the 'progressive' politics of London 2012: passing the 'Boyle test. Sociological Research Online, 18(12): available from http://www.socresonline.org.uk/18/2/18.html, (accessed 12 June, 2017).

Zanoni, P., Janssens, M., Benschop, Y. \& Nkomo, S. (2010) Unpacking Diversity, Grasping Inequality: Rethinking Difference Through Critical Perspectives. Organization, 17(1): 9-29.

\footnotetext{
${ }^{1}$ Black and minoritised ethnic (BME) is a popular acronym used in policy circles in the UK, used to denote the diverse positions and identities of racialised ethnic groups not included under the label of ethnic majority in the UK. We acknowledge that the term includes a huge amount of internal diversity.

${ }^{2}$ Replacing the Racial Equality Standard with a broader Equality Standard that includes issues of gender and disability as well as 'race' and ethnicity would complicate the ability to assess the effectiveness of race-related policies. Whilst this broader and more generic Standard was welcomed by some, many anti-racism advocates warned that the broader focus towards 'equality' may actually result in more limited work being undertaken into race equality (Carrington et al. 2016).
} 